\title{
The Specifics of Migration in Russian Regions
}

\author{
N.A. Eldyaeva ${ }^{1 *}$, E.S. Kovanova ${ }^{2}, O . G$. Lebedinskaya $^{1}$ and E.P. Tenetova ${ }^{1}$ \\ *Corresponding author: lebedinskaya19@gmail.com \\ ${ }^{1}$ Plekhanov Russian University of Economics, Moscow, Russia \\ ${ }^{2}$ Kalmyk State University named after B.B. Gorodovikov, Elista, Russia
}

\begin{abstract}
The world today is marked by strong migratory flows where Russia is not left behind by the global trends as the displacements of people between Russian regions and within a particular region are increasing that does not remain unnoticed for national and regional socio-economic development. The paper is aimed at identifying the specifics of the migration in Russian regions with special sampling and econometric models used to research into the interrelation 'migration - economy and social sphere'. The study has identified the specifics of the migration: the centralizing nature of migration flows and migrants gathering in a few certain large and favourable Russian territories; depopulation of rural territories in Russian regions, increasing migratory flows among young rural people, including women. The reason is in huge and growing imbalance between the levels of socio-economic development of municipal areas within a republic and across Russian regions.
\end{abstract}

Keywords: migration, labor migration, causes and consequences of migration, econometric modelling, Russian regions.

\section{Introduction}

The world today is marked by deep migration transformations. Migration is becoming a significant factor in the change of socio-economic situation, and its role is substantially increasing worldwide. Russia is not left behind by the global trends, and the migration of its population has an increasing impact on the country's development prospects. This impact can be both positive or negative and also differs between regions of origin and receiving regions [1]. Therefore more focus is to be placed on identifying qualitative and quantitative peculiarities of migration processes and their impact on the socio-economic development of the country and its regions.

\section{Problem Statement}

In view of a tremendous change in regional population structure, the estimation of the migration impacting regional socio-economic processes is increasingly problematic [2]. Contemporary research has detailed and exhaustive studies of the problem of economic and social factors impacting the volume and speed of migration flows [3, 4]. However, the inverse relationship 'migration - economy' remains still relatively unknown, with its great practical value for forecasting employment and unemployment and the dynamics of socio-economic development.

\section{Research Questions}

The development of a methodology for analyzing and modeling population migration involves solving a complex of complex issues of identifying specific features of the migration behavior of the population of the regions of the Russian Federation. For this, it is necessary to analyze the power of migration flows and their impact on the state and development of Russian regions. Next, identify the duration of return labor migration and its dependence on a complex of demographic and socio-economic factors. One of the most depressed regions of the Russian Federation, the Republic of Kalmykia, was subjected to a separate study.

\section{Purpose of the Study}

The aim of the study is a comprehensive and balanced analysis of the role of migration in the socio-economic development of the regions of the Russian Federation. Another, closely related to the first and most important research question, is to identify the factors that determine the effect of migration. Analyzing these problems logically implies consideration of the regional migration policy and an assessment of its ability to mitigate the negative consequences of the outflow of the population of the regions. 


\section{Research Methods}

The research used the approaches of panel data econometric models to study the interrelation between migration and the socio-economic development of Russian regions enabling to assess social and economic performance of Russian regions influenced by the amount and intensity of population migration. The sample valuably contributed to the population migration information base and enabled to research into the problems of migration and identify the peculiarities of migration flows associated with the specifics of Russian regions [5].

\section{Findings}

Migration is characterized by numerous positive and negative consequences increasingly impacting the socioeconomic development of Russian regions. Migration flows are heterogeneous in their spatial and temporal dynamics and have their specific features in each region which prejudges their different impact on the speed and variability of the socio-economic dynamics of Russian regions, the scope and intensity of their consequences. The complex study using modern analytical methods enabled to reveal the following:

- As a whole, population migration is characterized by the following trends. On the one hand, we can witness the centralizing population migration towards large Russian and regional cities. On the other hand, it is accompanied by the depopulation of regional rural territories. The reason is in huge and growing imbalance between the levels of socioeconomic development of municipal areas within the republic and across Russian regions.

- The study revealed that the migration of Russian regions has its peculiarities predetermining the diversity of its impact. It is about women and rural youth intensifying their migration. The next feature is that economic problems like low living standards and undeveloped labor market are among main motives about migration.

- Migration does not become a crucial means to improve the well-being of regional households as the inflows are spent on current consumption and have little impact on the material welfare of the republic's population and do not reduce its property differentiation.

- The sample revealed a returnable labor migration among the population of the region. The econometric model shows that the duration of labor migration greatly depends on the incomes of labor migrants, their age and educational level.

\section{Conclusion}

Russia is affected by deep migration processes, and they have a multiplier effect on current national development and determine its dynamics in the future. Being a complicated object to study, population migration is characterized by the variety of forms and kinds, multidirectional structure, the differentiation on the time and duration of migration processes as well as various interrelated conditions and elements.

The dynamics and anarchy of migration processes causes the need of continuous monitoring and regulation of migration at different levels of governance: national, regional and global. Currently, uncontrolled migration turns into the source of numerous problems of socio-economic and demographic development of both certain regions and the country as the whole. These problems are aggravated by the existing governance vacuum in the sphere of interregional migration.

Population migration reflects unsolved problems of socio-economic development and is a precise indicator of level and quality of life. Our time is often called 'a century of migration', 'a mobility century', 'the recent age of migration' in scientific literature $[1-3,5]$. The amounts and structure of migration flows are directly connected with growing differentiation of countries and Russian regions in income levels and quality of life.

Recent scientific literature has a great number of migration definitions supporting the general rule of defining complex research objects - the same thing can be differently classified in terms of a certain focus. The term 'migration' has two interpretations - a wide and a narrow one. The first wide approach treats migration as relocation [2]. This approach is the most commonly used in recent Russian and foreign scientific literature that is why our research is mostly based on it. One can note the versatility of that approach and its considerable analytical power for interpreting the interrelations between an individual and their living space: an individual and a household, an individual and a local community, an individual and the area they reside.

The acceleration of migratory movements increasingly changes its role in modifying the livelihood of the host society. Migration has begun to have both a direct and an indirect impact on various facets of this livelihood, and the changes associated with migration are both extensive and intensive. Many countries have had triggered a fierce debate over migration problems reflecting widely divergent views on it beginning with the most radical ones. Migration is very differently assessed: it can be viewed as a source of growing economy and a factor to hold up economic growth and recover job markets due to the competition between local labor force and migrants. Migration is believed to contribute to growing terrorism threats and further racial and ethnic conflicts.

The wide approach to studying migration is very much in line with the statistical hypothesis and provides a systematic approach based on an indicator system. Each region within the country is not a closed system, and migration processes depend on the respective processes in other parts and zones of the country. The system of migration indicators 
can be of two levels: the first level is represented by general indicators, the second level - by inter-district ones. General indicators are used to assess the amounts and the structure of population mobility of a given territory of the country and enable a comparative interregional analysis for estimating the rate of its change in time and space. These indicators provide information on the number of people entering or leaving as well as on growth or depopulation dynamics resulted from migration processes. Gross measures of migration and its structure are used to calculate additional indicators of in- and out-migration intensity characterizing stability level and population retention.

Structural characteristics of migration flows are within a certain group of indicators being of great value in migration analysis and prediction as its diverse impact on territories of origin and receiving territories greatly depends on these indicators. They are used to define the composition of migrants disaggregated by gender, age, place of residence, educational level nationality, etc. We should note the importance of a certain indicator - the proportion of young people among all migrants as it defines the impact of migration on the reproduction of population.

It must be pointed out that socio-economic and political changes have transformed migration flows directions and character. The directions of population migration have not remained unaffected: migrants tend to gather in central and South-Western Russia. There are several reasons for the centralizing character of migration flows in modern Russia:

1. The substantial differentiation in socio-economic development of Russian region impacts the attractivity of territories for migrants. Moscow, the Moscow Region and certain Russian regions are becoming powerful 'migration magnets' attracting both external and internal migrants. These regions need additional labor force and have diverse job markets with a higher wage level.

2. Favourable natural and climatic factors affect the intensity and nature of migration flows. Favourable climate, see coasts and developed resorts are instrumental in attracting migration to the regions in South Russia.

3. The approaches to developing regional policy are also different and predominant in the nature and scale of population migration.

The research has deeply examined a certain Russian subject - the Republic of Kalmykia that is a depressive agricultural region. Current demographic situation in the republic is marked by growing out-migration. In general, the data provided by regional statistics allow to assess the number and directions of regional migrants but do not enable to define structural characteristics and specifics of regional population migration.

The sampling conducted by the authors provides an adequate complement to the information bases of total and sample surveys of the population organized by the Federal State Statistics Service of the Russian Federation. The survey focuses on defining the numbers of internal and external migration, the directions and geography of regional migrants, reasons for migration and estimating returning labor migrants; assessing the impact of labor migration on the well-being of the population and balance in the local labor market; assessing the lifespan of internal labor migration.

The sample included 801 households in urban settlements and 1029 households in rural settlements. This structure of the selection reflects current displacement of regional population. The sample survey provided detailed and comprehensive information on the issues under analysis with the control over the accuracy of results and reduced labor and financial costs. The analysis showed that migration processes are very unstable in the region, however, they change their directions, scale, structure and intensity. Internal displacement predominates in regional migration flows, their proportion in gross migration turnover (the sum of arrivals and departures) amounts to 99 per cent, and their role in forming migration processes is constantly growing.

The structure of regional migration flows is the following one: a large proportion of all relocations accounts for regional migration including for the predominantly movements of rural inhabitants to urban settlements. However, the proportion of interregional migration has been constantly and dynamically growing, and the increase in the proportion of interregional movements indicates that the region participates actively in the interregional population exchange and has become its steady donor. In this context, population migration is a vital and crucial factor impacting population dynamics and regional population structure.

The results of the sample survey showed that rural youth has a high migratory mobility impacting the directions of migration flows. Regional migration gives way to interregional one. The numbers of rural youth regional migration are restrained by regional factors: high unemployment rate, low standards of living and subsidized regional budget.

Rural young people are more increasingly involved in migration processes that the same living in cities. This results in significant outflow of younger labor force from the countryside. The outlook, however, indicates that the growth of migratory mobility of rural youth toward the city may affect the deformation of age structure and ageing of rural population. Given the permanent nature and the prolonged economic crisis in regional agriculture, we can state s great loss of human capital that may prospectively affect regional socio-economic development and reduce its investment attractivity. Growing labor migration of rural youth may negatively result in the lack of qualified personnel in the main agricultural industry of the region.

The reasons for active out-migration of young people are the following ones. The proportion of young migrants leaving for the search of a job amounts to 21 per cent, and the proportion of migrants searching for a creative and interesting job amounts to 7 per cent. The respondents found that relocation and the following move were associated with a low level of well-being. Over 70 per cent pointed out that reason and, therefore, migratory motives of young people are of economic nature. As the survey showed, rural youth wants to get a good education. 19.2 per cent of respondents pointed out getting qualitative educations as the reason for migration.

The demographic situation in the whole country and its certain region has a great impact on different aspects of socio-economic development. The research showed that regional labor migration has peculiarities associated with gender predetermining the diversity of its impact. Women are more actively involved in migration processes. The 
sample survey showed that 57 per cent of prospective migrants are women. Their comparatively high migratory mobility is connected with a growing role of women in all life spheres including the labor one. We should note high educational level of female migrants. According to the survey, over 72 per cent of respondents have a university degree.

The research revealed the motives for female migration. Women aged 20 to24 tend to be involved in labor migration due to the absence of family and children which considerably increases the likelihood of relocation. The proportion of regional population likely to leave the region is declines with age, however, the wish to change their residence does not disappear.

The main problems facing migrants are housing needs and domestic problems ( 37.9 per cent) as well as legal issues (7.3 per cent). Administrative barriers and the difficulties of registering residence undermine the rights of labor migrants and produce an illegal sector. This is not economically viable for both the state and migrants. It seems useful to simplify the system of migrants' registration and at the same time to apply uniform criteria to primary record-keeping and methods for handling and generalizing information on labor migration.

However, the major problem of the region is not so much of expected high migratory mobility of women and rural youth but negative impacts of these migrants. Among theses impacts are enormous shifts and deformations in population structure and displacement derived over decades of migration movements. Women and youth out-migration will accentuate the constraints of demographic situation in the republic.

The sample survey revealed that labor migration in the region is returnable which means that a migrant returns to their place of permanent residence. In this regard, the estimation of its lifespan is of practical value because long- or short-term migration has serious implications for social, demographic and economic development of the territory. The term of labor migration may have a significant impact, for instance, while defining the prospects of building, services and trade development, estimating consumption level and quality of life, the likelihood of further migrating, marriage and birth rates. The sample survey showed that regional labor migration is of long-term nature, over 80 per cent of labor migrants are the so-called 'semi-permanent migrants' whose labor migration lasted for an average of 6 years. 5.3 per cent of persons surveyed leaved for a period of up to six months, and 10.8 per cent - for a period of six months up to one year.

The sample survey revealed the problems of current registration of migrants in Russia, as only 48 per cent of people surveyed removed from civil registry of residence, the rest have leaved on the other territory for a long time but were part of resident population of their territory.

Econometric modelling enabled to reveal the complex of socio-economic and demographic factors and estimate the impact of each factor on the term of labor migration. The results of modelling showed that the term of labor migration depends on incomes of labor migrants, their age and educational level, with the economic factor being the most important in making decisions about the term of migration. The change of day-to-day life, leaving home, parting with family and friends, administrative barriers cannot influence the decision to improve the material situation. In the light of aggravated crisis in regional economy and social sphere, it can be concluded that the economic factor not only remains valid, it will be dominant for a long time.

\section{References}

1. D.G. Papademetriou, D. Meissner, New migration thinking for a new century. Migration Policy Institute, December, 15 (2006).

2. S. Castles, H. de Haas, M.J. Miller, The age of migration: International population movements in the modern world. New York, N.Y.: Palgrave Macmillan (1993).

3. E.G. Ravenstain, The Birthplace of the people and the laws of migration. The Geographical Magazine, 3, 173-177, 201-206, 229-233 (1876).

4. M.P. Todaro, Internal migration in developing countries. Geneva: International Labor Office (1976).

5. E.V. Sibirskaya, L.V. Oveshnikova, L.A. Mikheykina, I.R. Lyapina, Statistics of living standards of population. Studies in Systems, Decision and Control, 158, 23-37 (2019). 